\title{
Manufacturing System Design Decomposition for Sustainability
}

\author{
Marco Taisch, Bojan Stahl, Gokan May, and Matteo Cocco \\ Politecnico di Milano, Department of Management, \\ Economics and Industrial Engineering, Milan, Italy \\ \{marco.taisch, bojan.stahl, matteo.cocco\}@polimi.it
}

\begin{abstract}
The paper provides insights into the operations strategy definition process. While literature seeks the concept of manufacturing strategy content with competitive priorities, decision categories and manufacturing capabilities to explain strategy definition ambitions, practice shows difficulty in applying this high level concept in practical terms. Sustainability and the wide array of incorporation opportunities and policies make it difficult for companies to leap the gap towards a truly sustainably firm. Based on the methodology of axiomatic design, the study develops in a prescriptive research setting a metaframework for supporting strategy definition in manufacturing firms.
\end{abstract}

Keywords: sustainability, manufacturing strategy, axiomatic design.

\section{Introduction}

How firms can turn sustainable manufacturing into a competitive weapon, so as to alleviate upstream and downstream performance improvements along the triple bottom line, while reducing environmental harm and stimulating social solidarity, is a major area for research [1]. The development and deployment of adequate sustainable manufacturing strategies are still open issues and of utmost interest both for research and practice [2].

Besides a lack of process deployment as well as trade-off understanding, the definition of a sustainable manufacturing strategy coherent with other functional and business strategies is a practical gap [3]. Especially the internal consistency of manufacturing strategy, i.e. the translation of competitive priorities into decision categories in order to form, expand or maintain manufacturing capabilities, and the design of appropriate manufacturing improvement programs to enable strategic choices, is a major obstacle for companies nowadays. The development of competitive edge is not led to by the linear adding of pollution prevention projects or by the adoption of certain environmental or social standards or certifications following the motto one size fits it all. Moreover, taking the XPS (company-specific production system) approach as a model for designing firm-tailored production systems [4], in the same way firms have to be capable to tailor their strategy to their system, structure, culture and product in order to reach beyond low hanging fruits benefits. In this article, we propose a framework based on Axiomatic Design (AD) principles which can guide top management and decision-makers in operationalizing their firm's manufacturing strategy.

B. Grabot et al. (Eds.): APMS 2014, Part II, IFIP AICT 439, pp. 254-261, 2014.

(C) IFIP International Federation for Information Processing 2014 


\section{Background}

Manufacturing strategy as a discipline was initiated ca. 40 years ago as it was recognized by US scholars that linking long-term decisions in manufacturing with business strategy may have a positive impact on business performance and create competitive advantage [5]. Manufacturing strategy is the deployment and adjustment of manufacturing capabilities by patterns of decisions to efficiently and effectively exploit the manufacturing function by means of its resources for the purpose of maximizing the competitive advantage while maintaining consistency with higher corporate goals and strategies. Based on the pioneering work of Wickham Skinner, two different research streams have emerged in the field: manufacturing strategy content and manufacturing strategy process.

The research on content sets the substance of decisions and its junction into the focus and accompanying changes in the structure and infrastructure of a firm's manufacturing system. The research on process on the other hand enlightens the ways in how strategy is formulated and operationalized. Another popular term used by scholars here is also manufacturing strategy formulation or formation. Leong et al. (1990) introduced the predominant theoretical construct in manufacturing strategy content which is composed of competitive priorities, decision categories and manufacturing capabilities [6]. Krajewski and Ritzman define competitive priorities as "the dimensions that a firm's production system must possess to support the demands of the markets that the firm wishes to compete in" [7]. The strategic choices made in manufacturing strategy can be classified into structural and infrastructural decision areas [8]. Decisions in the structural area have influence on the physical resources, while infrastructural decision impact their relationship and activities within operations. Most decisions cannot be ordered along these archetypes, but have a hybrid effect. While competitive priorities are intended capabilities and future models of the strengths of the company, manufacturing capabilities are priorities put in practice or priorities put to work via decision categories [9]. Manufacturing capabilities refer therefore to a firm's operations performance relative to its competitors, and the alignment of priorities and capabilities, i.e. creating good strategic fit, reflects an efficient and effective allocation of resources for capability development [10].

The advancement within the manufacturing strategy process research is rived into macro and micro process views. The macro process view is characterized by a topdown approach, with the aim of emphasizing the link from business strategy to the functional manufacturing strategy, and the focus towards the consistency of hierarchy of strategies. On the other hand, the micro process view is made upon bottom-up or integrative views, emphasizes the link of the manufacturing strategy to the manufacturing function, and the translation function of competitive priorities into strategic manufacturing initiatives [11].

The introduction of sustainability into research on operations management has gained large popularity among scholars. Kleindorfer et.al (2005) define sustainable $\mathrm{OM}$ as "the set of skills and concepts that allow a company to structure and manage its business processes to obtain a competitive return on its capital assets without sacrificing the legitimate needs of internal and external stakeholders and with due regard for the impact of its operations on people and the environment" [1]. 
Sustainability in manufacturing strategy as a research endeavor has gained momentum. In the past years research was mainly empirically investigating the introduction of sustainability as a competitive priority in the corporate agenda. Most researchers have focused on the environmental pillar in their studies, while social pillar has received less attention. Findings are contradictory with no or little explanation for differentiations. While some studies refuse the hypothesis of sustainability as a competitive priority [12], others include it successfully in other manufacturing strategy constructs like the extended sandcone model [13]. While researchers have mainly focused on scientific inquiries on competitive priorities, the areas of decision categories or the entire spectrum within the manufacturing strategy process field are largely neglected. The aim of the paper is to fill this gap and develop a practical framework to incorporate sustainability into manufacturing strategy content.

\section{Methodology}

Past research in the field was largely empirically driven. Although this is needed and relevant, the theoretical, prescriptive, and modern perspective might be lost and leave innovative ideas and concepts aside.

The research endeavour takes over a pragmatist epistemological point of view in a prescriptive research setting. The research question is: how can firms translate the sustainability principle into their manufacturing strategy. Since a pattern or methodological guidance cannot be gathered from its complex environmental situation due to lack of empirical studies and lack of proven approaches, we decided to embed our research in a prescriptive research setting. It enables us to design an approach based on axiomatic instead of empirical reasoning. Through deductive reasoning we can apply and test the approach in a case setting, which in turn can serve later as inductive testing for empirical-based research.

This paper reports research in which axiomatic design methodology is used to model the strategy content of a sustainable manufacturing system which consist of functional requirements, design parameters and process variables. Axiomatic design (AD) as a design framework was created by Professor Suh of the Massachusetts Institute of Technology [14]. Here, design is seen as the interplay between "what we want to achieve" and "how we want to achieve"; thus consistently differentiating between goals and means (or solutions). Typically the design process follows a five step procedure, i.e. identifying customer needs, problem definition (problem to solve for need satisfaction), solution(s) creation, analysis and optimization, solution fit. Using the Axiomatic Design approach by Suh, sustainability goals are purposely translated into functional requirements. The four main concepts around axiomatic design are domains, hierarchies, zigzagging and design axioms.

Typically there are four domains distinguished (see Figure 1). Left domains define what should be achieved while right domains defines how it should be achieved. The customer domain contains customer requirements, needs, expectations, specifications and anticipations. These are then translated into the functional domain as functional requirements (FR). Functional requirements are independent from each other and 
characterize the minimum solution to a given design problem. The design parameters (DP) are specifications within the solution in the physical domain that are chosen to specify the FRs. In the same way, process variables (PV) characterize the process that satisfies the DPs in the process domain.

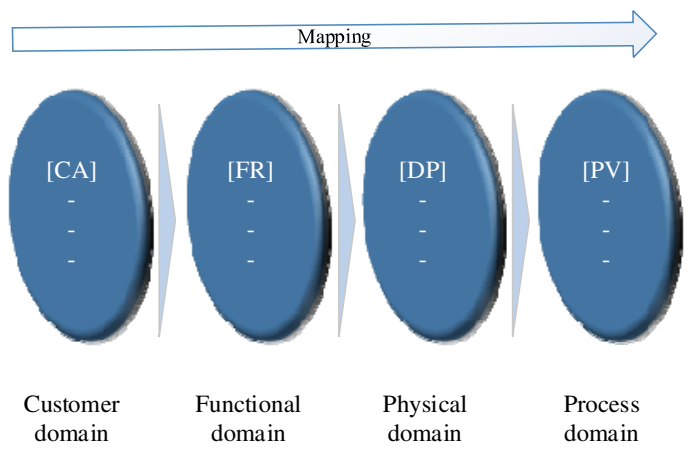

Fig. 1. Domain perspective in Axiomatic Design

Hierarchies are the second main concept in axiomatic design. Hierarchies refer to the design architecture of a model. Decomposition is a terminology often used in this junction and refers to the development of functional requirements and design parameters in the next lower level based upon the next higher level FRs and DPs. This process is iterated until concreteness for implementation is reached. At the end the model is composed of different levels of hierarchies.

The third main concept of axiomatic design is zigzagging that describes the process of decomposing the design into hierarchies by alternating between pairs of domains. Hereby, starting from e.g. of the FR 1 of hierarchical layer a, the designer crosses domains and chooses design parameter 1 for the same hierarchical layer and then crosses again domains and goes back to the functional domain to define sub-level requirements of FR1.

The fourth concept is design axioms. Two axioms provide a basis for the best fit selections among different design scenarios. The Independence Axiom states that the independence of the FRs must be maintained. This means that in an acceptable design, a DP can be adjusted to satisfy its corresponding FR without affecting other FRs. And the Information Axiom states that the information content must be minimized. Of the alternative designs that fulfill the Independence Axiom the best design has the minimum content. It can be translated that simpler designs are more preferable to other designs.

The relationship between FRs and DPs is given as follows:

$$
\{F R\}=[A]\{D P\}
$$

$\mathrm{A}$ is the design matrix from which each element can be expressed as

$$
A_{i j}=\partial F R_{i} / \partial D P_{j}
$$


Each line of the vector stated in (1) can be written as

$$
F R_{i}=\sum A_{i j} D P_{j}
$$

Similarly the relationship between DPs and PVs is described by a design matrix $\mathrm{B}$ as

$$
\{D P\}=[B]\{P V\}
$$

Hence, including (4) into (1), the FRs can be defined as

$$
\{F R\}=[A][B]\{P V\}
$$

The relationship between FR-DP-PV through the design matrix A and B is important for the satisfaction of the independence axioms.

To satisfy the axiom designs have to be uncoupled or decoupled, while coupled designs infringe the axiom. A design is uncoupled if the design matrix is diagonal; and a design is decoupled if the design matrix is triangular. In a decoupled design the path dependency becomes critical. Coupled designs are inferior since it is impossible to adjust either DP without affecting other FRs. Hence, the construct of the desired FR can only achieved by a iterative trial-and-error procedure. In the following, a glance at sustainable manufacturing system decomposition is presented.

\section{Axiomatic Model of Sustainable Production Systems}

\subsection{Viability as Firm's Objective}

In the following we state that the major objective of a sustainable firm is not solely including environmental soundness and social solidarity into their corporate agenda. The major objective is to maximize the viability of the firm. Here, viability is defined according to the systems theory or cybernetics perspective, i.e. maintaining a separate existence. Viability means that a determined configuration of states can be maintained by the organization without time constraints. To emphasize this, from a cybernetic point of view viability is a typical metasystemic measure for the assessment of a system concerning its structural effectiveness. Viability in enterprise context means to maintain a change process due to its environment, its identity, and its primary activities and due to itself [15].

\subsection{First Level Decomposition}

Based on the concept of viability, all organizations pursue it as their ultimate goal. Viability is the central focus of an organizations purpose and all activities within the organization should be allocated to this target. It is assumed that pursuing sustainability in the broader sense enables an organization to fulfill the viability principle in the best way. Figure 2 shows the top FRs, DPs and PVs as well as the FRs of the first level decomposition based on the viability principle for a manufacturing system pursuing sustainable strategy. 


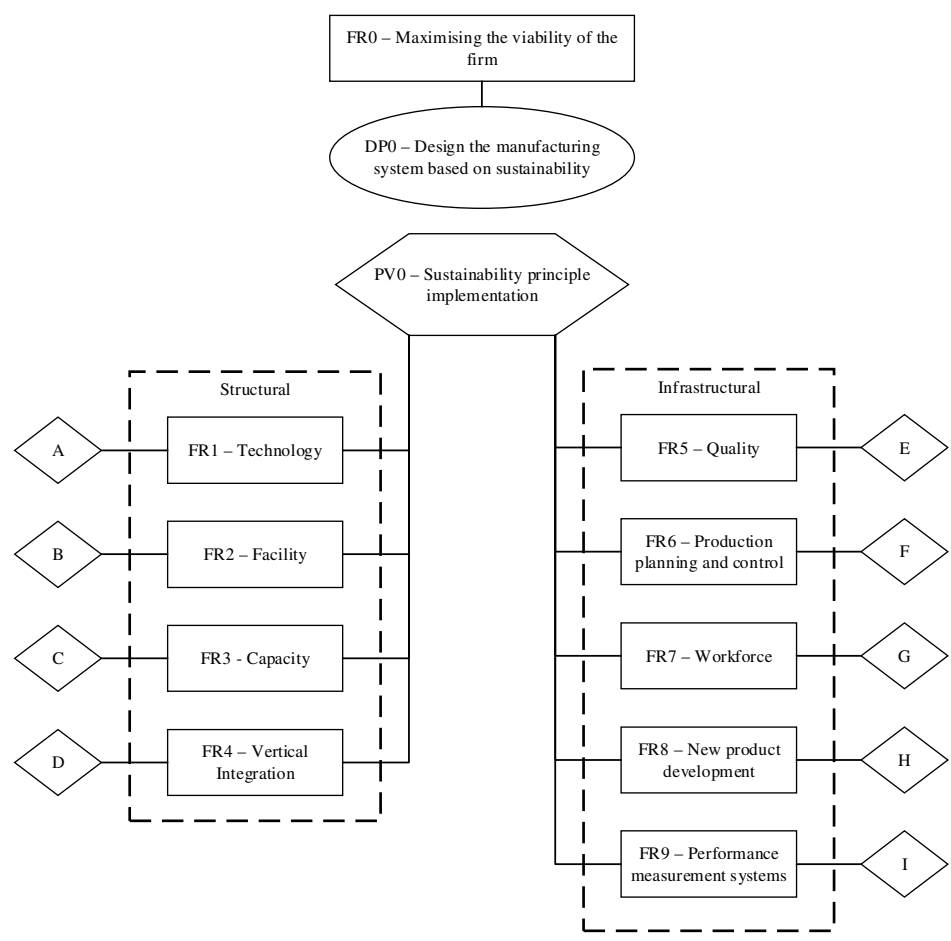

Fig. 2. Organization's top level domain and first decomposition

The technology (FR1) as well as capacity (FR3) asserts emphasis on the product type, i.e. either high volume and undifferentiated or low volume and customer specific. Regarding the vertical integration (FR4) decision-makers ponder developing and producing parts on their own or buying them in. Vertical integration might not only apply to product parts, but to entire departments or product families. The size, capacity and location (FR2, FR3) of facilities are of utmost interest in the manufacturing strategy planning activities. While large factories support economies of scales and high volume production, smaller factories are easier to align to flexibility. The plant location (FR2) may be chosen due to different factors including location of raw material and component suppliers, location of customers, transportation and communication systems, qualification of workforce, legislation and taxes. These structural decisions are added by infrastructural decisions. Production and inventory planning as well as accordant control systems (FR6) are putting two major decisions in place, i.e. centralization and decentralization as well as pull or push systems of the factory. The organizational structure of factories can be based on normality, i.e. hierarchical structure and cost center orientation with clear procedures and low level of decision making, or on autonomy, i.e. viewing the factory as a profit center with enriched degrees of freedom for the middle managers and workforce in making decisions to solve operational problems. Human resource management (FR7) around manufacturing strategy involves areas like payment system, recruitment process, worker-to-job assignment, incentive policies and so on. Quality management (FR5) can be spread 
from the entire spectrum from merely statistical process control to an entire production philosophy. New product development (FR8) and performance measurement systems (FR9) finalize the infrastructural decision categories that are high level functional requirements for a sustainable manufacturing system.

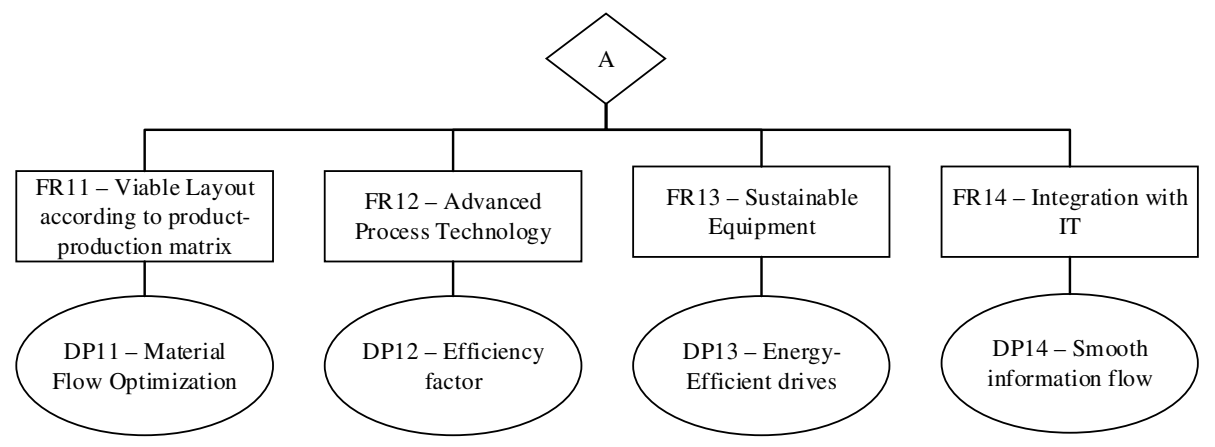

Fig. 3. Second level decomposition of FR1-Technology

The second level decomposition for FR1-Technology is shown as an example (Figure 3). FR1 is decomposed in four sub-FRs. These sub-FRs are the main requirements that are needed to fulfill the primary FR1 objective. Extracted from an example it can be seen that FR11 and FR13 are tailored towards environmental soundness and FR12 and FR14 serve the competitive priorities cost as well as delivery. This decomposition should be done among all decision criteria. Furthermore, the decomposition should be performed in recursions until saturation and clarity of the objectives and the method to reach them is arrived. While in the second recursion the FRs are still quite abstract, following decompositions can define in detail the requirements, parameters and variables for a sustainable manufacturing system.

\section{$5 \quad$ Summary and Outlook}

The study presented in the paper developed a framework for the design of a sustainable manufacturing systems and the definition of a sustainable manufacturing strategy. The framework is based on Axiomatic Design principles and builds upon decision categories developed in manufacturing strategy. The research serves two major contributions. First, it presents a scientifically motivated hands-on approach for decision makers to define their firm's manufacturing strategy content. Second, it supports the neglected integration of product and production focus in manufacturing strategy which was largely disregarded in the field of operations management.

The research faces two major limitations. First, an application case is mandatory to manifest the value potential of the approach and should be done in future work. Second, other tools in strategic management like scenario technique or SWOT analysis etc. have not been yet considered, hence predictions how the AD approach can be used in combination with other established techniques is not clear. 
Future research shall concentrate on overcoming the above stated limitations. Furthermore, and of utmost importance, is to bridge the gap between strategy definition and strategy implementation. While it is among scholars commonly accepted that manufacturing improvement programs are the way to operationalize manufacturing strategy and build up capabilities, it is theoretically and practically unclear how to translate a defined strategy into concrete actions without lining up certain programs and certifications, but heaving the manufacturing system beyond the low hanging fruits.

Acknowledgements. This work was partly funded by the European Commission through the Linked Design Project (FP7-2011-NMP-ICT-FoF, http://www. linkeddesign.eu/). The authors wish to acknowledge their gratitude and appreciation to the rest of the project partners for their contributions during the development of various ideas and concepts presented in this paper.

\section{References}

1. Kleindorfer, P.R., Singhal, K., van Wassenhove, L.N.: Sustainable Operations Management. Prod. Oper. Manag. 14(4), 482-492 (2005)

2. Drake, D.F., Spinler, S.: Sustainable Operations Management: An enduring stream or a passing fancy? Manuf. Serv. Oper. Manag. 15(4), 689-700 (2013)

3. Mirvis, P., Googins, B., Kinnicutt, S.: Vision, mission, values: Guideposts to sustainability. Organ. Dyn. 39(4), 316-324 (2010)

4. Netland, T., Aspelund, A.: Company-specific production systems and competitive advantage: a resource-based view on the Volvo Production System. Int. J. Oper. Prod. Manag. 33(11/12), 1511-1531 (2013)

5. Demeter, K.: Manufacturing strategy and competitiveness. Int. J. Prod. Econ. 81-82(1), 205-213 (2003)

6. Leong, G.K., Snyder, D.L., Ward, P.T.: Research in the process of manufacturing strategy. Omega 18(2), 109-122 (1990)

7. Krajewski, L.J., Ritzmann: Operations Management: Strategy and Analysis, 3rd edn. Addison-Wesley, Wokingham (1993)

8. Hayes, R.H., Wheelwright, S.C.: Restoring our competitive edge: competing through manufacturing. Wiley and Sons, New York (1984)

9. Ward, P.T., Bickford, D.J., Leong, G.K.: Configurations of manufacturing strategy, business strategy, environment and structure. J. Manage. 22(4), 597-626 (1996)

10. Schoenherr, T., Narasimhan, R.: The fit between capabilities and priorities and its impact on performance improvement: revisiting and extending the theory of production competence. Int. J. Prod. Res. 50(14), 3755-3775 (2012)

11. Kim, J.S., Arnold, P.: Operationalizing manufacturing strategy - an exploratory study of constructs and linkage. Int. J. Oper. Prod. Manag., Bol. 16(12), 45-73 (1996)

12. Thuerer, M., Filho, M.G., Stevenson, M., Fredendall, L.D.: Competitive priorities of small manufacturers in Brazil. Ind. Mang. Data Syst. 113(6), 856-874 (2013)

13. Avella, L., Vazquez-Bustelo, D., Fernandez, E.: Cumulative manufacturing capabilities: an extended model and new empirical evidence. Int. J. Prod. Res. 49(3), 707-729 (2011)

14. Suh, N.P.: Axiomatic Design. Oxford University Press, New York (2001)

15. Beer, S.: The Heart of Enterprise. Wiley, Chichester (1979) 